BBABIO 43289

\title{
Activation of beef-heart cytochrome $c$ oxidase by cardiolipin and analogues of cardiolipin
}

\author{
Dorota A. Abramovitch ${ }^{1}$, Derek Marsh ${ }^{2}$ and Gary L. Powell ${ }^{1}$ \\ ${ }^{\prime}$ Department of Biological Sciences, Clemson University, Clemson, SC (U.S.A.) and ${ }^{2}$ Max-Planck-Institut für biophysikalische Chemie, \\ Abt. Spektroskopie, Göttingen (Nikolausberg) (F.R.G.)
}

(Received 12 March 1990)

Key words: Diphosphatidylglycerol; Cardiolipin; Cardiolipin analog; Lysocardiolipin; Cytochrome $c$; Electrostatics; Cholate exchange

Beef-heart cytochrome $c$ oxidase lacking endogenous lipids can be prepared by cholate-mediated exchange with dimyristoylphosphatidylcholine (Powell, G.L., Knowles, P.F. and Marsh, D. (1985) Biochim. Biophys. Acta 816, 191-194). These preparations retained practically no endogenous cardiolipin (less than 0.19 mol cardiolipin per mol of oxidase) but in Tween 80 they retained unaltered electron transport activity. Resupplementation of the dimyristoylphosphatidylcholine-substituted cytochrome oxidase with cardiolipin and cardiolipin analogues with different numbers of acyl chains or with a methylated headgroup enhanced the activity of the reconstituted enzyme to an extent dependent on the structure of the cardiolipin derivative. The Eadie-Hofstee plot showed biphasic kinetic behavior for all reconstituted preparations, even those completely lacking cardiolipin. This biphasic substrate dependence of the kinetics was simulated using the model of Brzezinski, P. and Malmström, B.G. (Proc. Natl. Acad. Sci. USA 83 (1986) 4282-4286), which implicates two interconverting enzyme conformations in the proton transport step. The activation of cytochrome $c$ oxidase by the cardiolipin analogues could be explained in terms of an electrostatic enhancement of the surface concentrations of both cytochrome $c$ and protons, and a facilitated interconversion between the two enzyme conformations.

\section{Introduction}

The interaction of cardiolipin with mitochondrial cytochrome $c$ oxidase continues to be of interest for several reasons, particularly as an example of an apparently specific lipid-protein interaction with important functional consequences. Cytochrome oxidase is the terminal electron acceptor, the most abundant component of the electron transport system and may be the major regulatory component [1]. Cardiolipin, or diphosphatidylglycerol, is a phospholipid of unusual structure

\footnotetext{
Abbreviations: DMPC, 1,2-dimyristoyl-sn-glycero-3-phosphocholine; acyl cardiolipin (or acylCL), 1,3-bis(1,2-diacyl-sn-glycero[3]phospho)2-oleoyl-sn-glycerol; dilysocardiolipin (or dilysoCL), 1,3-bis(1-acyl-2lyso-sn-glycero[3]phospho)-sn-glycerol; monolysocardiolipin (or monolysoCL), 1-(1,2-diacyl-sn-glycero[3]phospho)-3-(1-acyl-2-lysosn-glycero[3]phospho)-sn-glycerol; dimethylcardiolipin (or DiMeCL), 1,3-bis(1,2-diacyl-sn-glycero[3](3-O-methyl)phospho-sn-glycerol; CL, beef-heart cardiolipin; TMPD, $N, N, N^{\prime}, N^{\prime}$-tetramethyl-p-phenylenediamine.
}

Correspondence: G.L. Powell, Department of Biological Sciences, Clemson University, Clemson, SC 29634-1903, U.S.A. localized almost exclusively within the mitochondrial membrane [2] where it is biosynthesized. This lipid may interact with other intrinsic membrane components of the inner mitochondrial membrane, but its interaction with cytochrome oxidase has been best characterized. The availability of a spin-labeled derivative of cardiolipin [3] has permitted direct measurements of the relative association constant of this lipid at the boundary layer of cytochrome oxidase [4,5]. Comparison of the relative association constants of various spin-labeled phospholipids for intrinsic membrane enzymes has shown that cardiolipin exhibits an especially high affinity for cytochrome oxidase and that this affinity is not general for other membrane proteins [6]. The association of spin-labelled cardiolipin with the reconstituted membranous form of this enzyme was shown to be a feature of the entire hydrophobic surface of the protein with highly localized specific binding sites for cardiolipin being absent [7]. This conclusion is also consistent with recent studies using photoactivatable cardiolipin analogues [8].

Proposals regarding the function of cardiolipin, which copurifies with cytochrome oxidase [9], are based prim- 
arily upon observations that the enzyme activity was enhanced in the presence of this phospholipid [10]. Delipidation techniques leave a few moles of residual cardiolipin, and not only was activity efficiently restored upon supplementation with cardiolipin [11-13], but also cardiolipin provided the highest activity [14]. These results have been interpreted as demonstrating that cardiolipin is essential for the activity of cytochrome oxidase [2]. The substrate for this enzyme is the basic protein, cytochrome $c$, which has been shown to interact in vitro with cardiolipin [15], and it has been suggested that cardiolipin enhanced activity by mediating the binding of cytochrome $c$ at a low affinity site $[16,17]$.

To test these suggestions more critically, cytochrome oxidase devoid of cardiolipin was prepared by lipid substitution with dimyristoylphosphatidylcholine [18]. Evidence is given showing that this endogenous lipid was reduced to levels of less than $0.19 \mathrm{~mol}$ per mol enzyme. The DMPC-exchanged enzyme, while retaining reasonable activity in the absence of cardiolipin, showed enhanced activity when supplemented with cardiolipin. The functions of cardiolipin proposed earlier were examined in these systems with defined lipid composition.

Four recently described cardiolipin derivatives [19], dimethylcardiolipin, mono-, dilyso- and acylcardiolipin (cf. Fig. 1), were shown to activate this enzyme to different extents. Dimethylcardiolipin bears no charge at the two phosphodiester groups; dilyso- and

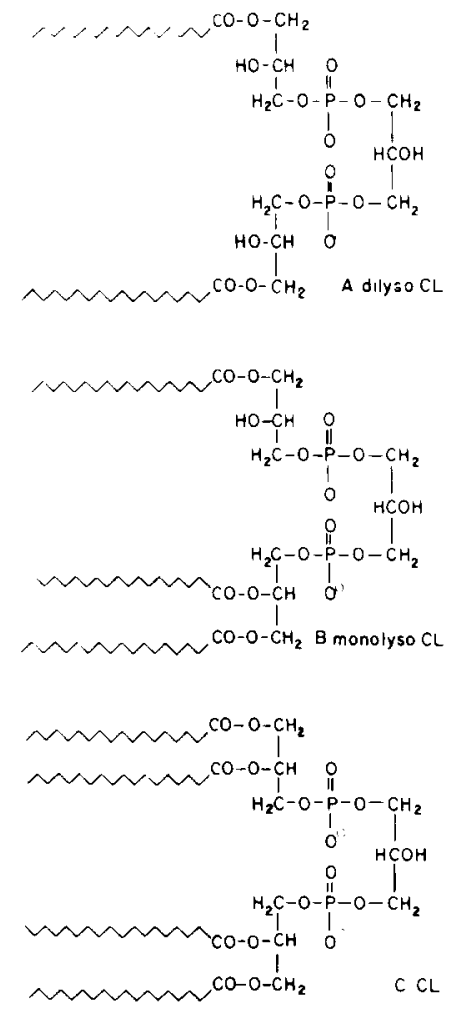

Fig. 1. Structures of cardiolipin and cardiolipin analogues. Systematic names are given under the abbreviations. The lipid chain composition is approx. $90 \%$ linoleate [7], except that the center chain of acyl $C L$ is oleate. acylcardiolipin assume non-bilayer phases, while monolysocardiolipin forms bilayers even at high salt concentrations [19]. All four derivatives associate relatively strongly with the enzyme [20]. The ability of these analogues to activate the enzyme is discussed in terms of their structural differences. Simulation of the kinetics is used to support the conclusion that the ability of cardiolipin to increase the activity of cytochrome oxidase is based both on the increased surface charge conferred by cardiolipin at the boundary layer of the enzyme and on an enhanced interconversion between different conformations of the enzyme in a cardiolipin-enriched environment.

\section{Materials and Methods}

Horse-heart cytochrome $c$ (Type VI - Sigma, St. Louis, MO) was reduced using dithionite and separated on Sephadex G-25 (Pharmacia, Piscataway, NJ), or used in the oxidized form. Beef-heart cardiolipin was obtained from Sigma. The cardiolipin derivatives with methylated phosphate groups or with different numbers of acyl chains (see Fig. 1) were prepared from beef heart cardiolipin. Monolysocardiolipin was purchased from Avanti Biochemicals (Birmingham, AL); TMPD, DMPC, sodium cholate, cacodylic acid and other biochemicals were purchased from Sigma. Other chemicals were of the highest purity grade available.

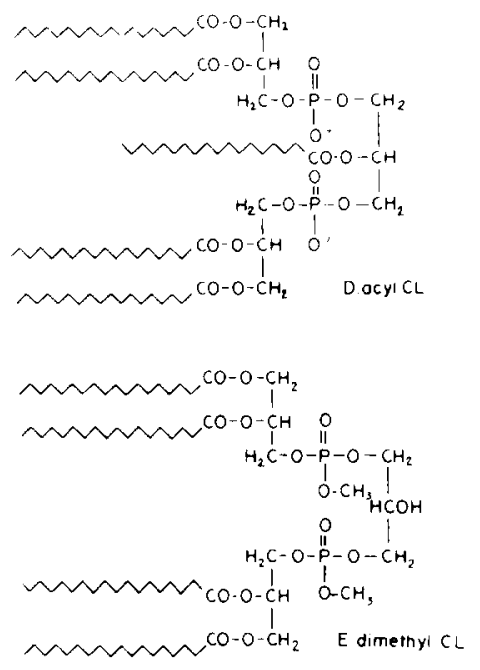

are given under the abbreviat
center chain of acyl $C L$ is oleate. 
Lipid-poor cytochrome $c$ oxidase was prepared from beef-heart particles by the method of Yu et al. [10] as modified by Cable and Powell [4] and had the properties described previously $[4,10]$. Aliquots $(16 \mathrm{mg}$ protein) of this preparation were then exchanged three times with a $1000 \times$ molar excess of DMPC $[7,18]$. The final precipitate was dissolved in $0.7 \mathrm{ml} 1 \%$ cholate, 10 $\mathrm{mM}$ Tris- $\mathrm{HCl}$ and $1 \mathrm{mM}$ EDTA (pH 7.4) and centrifuged at $27000 \mathrm{rpm}$ for $15 \mathrm{~min}$. The supernatant contained 8-10 $\mathrm{mg}$ of protein, and had a lipid/protein ratio of 40-50 mol of DMPC per mol of enzyme and a heme $a$ to protein ratio of $8-10 \mathrm{nmol} / \mathrm{mg}$, using the Lowry assay for protein [21]. This lipid concentration estimated from phosphate content $[22,23]$ still classifies this preparation as lipid-poor; assay in buffer with no supplements showed low but measurable activity [7]. However, if assayed spectrophotometrically using the procedure described by Yonetani [24] after solubilizing the enzyme in 1\% Tween 80 and dialysis against $0.1 \%$ Tween 80 in $10 \mathrm{mM}$ potassium phosphate $(\mathrm{pH} \mathrm{7.4)}$ overnight, the molecular activity was $9000-11000 \mathrm{~min}^{-1}$ $\left(150-180 \mathrm{~s}^{-1}\right)$. This activity was comparable with the highest activity given for the Yonetani preparation [24] and was the same as the activity measured for the starting preparation containing endogenous lipid when dialyzed against Tween 80 as above.

The fraction of the total phospholipid content that corresponded to residual endogenous lipid was estimated from the methyl linoleate content after in situ transesterification: $10 \mathrm{mg}$ of the DMPC-reconstituted enzyme was lyophilized, and taken up in $0.5 \mathrm{ml}$ of methanol which contained $4 \mathrm{~g} \mathrm{HCl}$ per $100 \mathrm{ml}$. The suspension was heated to $50^{\circ} \mathrm{C}$ for $5 \mathrm{~min}$ in a water bath. The volume was reduced to half under argon and an equal volume of $40-60 \%$ petroleum ether added, the mixture was then mixed vigorously and a $5 \mu 1$ aliquot of the supernatant injected for gas-liquid chromatography. The fatty methyl esters were separated isothermally at $180^{\circ} \mathrm{C}$ on a $6 \mathrm{ft}-1 / 8$ inch stainless steel column containing $10 \%$ SP-2330 on $100 / 120$ Chromosorb WAW at a $\mathrm{N}_{2}$ flow rate of $19 \mathrm{ml} / \mathrm{min}$., using a Hewlett-Packard $5830 \mathrm{~A}$ gas-liquid chromatograph with digital integration of the flame ionization signal. The fatty acids were identified from the retention times of standards. Methyl linoleate was verified by catalytic hydrogenation [25], which caused the disappearance of the 9.23 min peak and an increase of the peak at 6.22 min (methyl stearate). These results, expressed as moles of endogenous lipid, are summarized in Table $I$.

The in situ transesterification procedure outlined above avoids potential problems which might arise from incomplete extraction of the endogenous lipids. The phospholipids are converted to their methyl esters in situ, and a preferential binding of the fatty acid methyl esters to the protein seems unlikely. To eliminate completely the possibility that the protein retained
TABLE I

Cardiolipin content of preparations of beef-heart cytochrome oxidase

\begin{tabular}{|c|c|c|c|}
\hline Enzyme & $\begin{array}{l}\text { Total } \\
\text { phospholipid } \\
\text { (mol phosphate }^{\mathrm{b}} \\
\text { per mol enzyme) }\end{array}$ & $\begin{array}{l}\text { Methyl } \\
\text { linoleate } \\
\text { (\% of acyl } \\
\text { residues) }\end{array}$ & $\begin{array}{l}\text { Cardiolipin }^{\mathrm{d}} \\
\text { (mol per } \mathrm{mol} \\
\text { enzyme) }\end{array}$ \\
\hline With endogenous lipid ${ }^{a}$ & 41.6 & 17.8 & 4.26 \\
\hline \multirow{4}{*}{$\begin{array}{l}\text { DMPC exchanged } \\
\text { supplemented with } 1 \\
\text { mol of cardiolipin } \\
\text { proteolyzed } \\
\text { supplemented with } 1 \\
\text { mol of cardiolipin } \\
\text { and proteolyzed }\end{array}$} & 36.1 & 0.32 & 0.06 \\
\hline & 38.1 & 3.94 & 0.71 \\
\hline & 65.9 & 0.51 & 0.19 \\
\hline & 67.9 & 2.7 & 1.0 \\
\hline
\end{tabular}

a This enzyme corresponds to the lipid-rich preparation of Ref. 10, containing $11 \%$ cardiolipin.

b Estimated from total digestion of the lipid-protein complex in perchloric acid, followed by phosphate [21] and protein [20] determination, assuming $2 \cdot 10^{5} \mathrm{mg}$ protein $/ \mathrm{mmol}$ enzyme.

c Estimated by gas-liquid chromatography and digital integration of all the fatty acid methyl esters.

d Calculated as the fraction of the total phospholipid (as phosphate) containing linoleate. Cardiolipin (CL) contains $2 \mathrm{~mol}$ of phosphate per mol of lipid and $87 \%$ linoleate [7]. Thus $\mathrm{CL}=$ total phospholipid $\times$ linoleate $/(2 \times 0.87)$.

cardiolipin, the enzyme was fully proteolyzed by incubation of $10 \mathrm{mg}$ of the oxidase with $0.2 \mathrm{mg}$ Proteinase $\mathrm{K}$ (Sigma) and $0.2 \mathrm{mg}$ thermolysin (Type $\mathrm{X}$ proteinase from Bacillus thermoproteolyticus, Sigma) in $10 \mathrm{mM}$ Tris- $\mathrm{HCl}$ ( $\mathrm{pH}$ 7.4) containing $1 \%$ sodium dodecylsulfate, at room temperature $\left(21^{\circ} \mathrm{C}\right)$ overnight. SDSPAGE electrophoresis [26] was carried out to verify complete digestion (no remaining distinct protein bands). After methanolysis the endogenous lipids were characterized by GLC as above.

Cholate dilution [27] was used for both spectrophotometric [28] and polarographic [29] activity assays. The effects of different lipid environments were investigated with the spectrophotometric assay by cosolubilizing enzyme $(6 \mu 1$ of $6.3 \mathrm{mg} / \mathrm{ml})$ with samples of DMPC, cardiolipin or cardiolipin analogue which had been dried in the bottom of a vial and dissolved in $0.5 \mathrm{ml}$ of $0.5 \%$ cholate, $10 \mathrm{mM}$ Tris- $\mathrm{HCl}$ and $0.1 \mathrm{mM}$ disodium EDTA ( $\mathrm{pH}$ 7.4). The spectrophotometric assay was carried out with $4 \mathrm{nM}$ enzyme in $1 \mathrm{ml}$ of $40 \mathrm{mM}$ potassium phosphate $(\mathrm{pH}$ 6.7). The specific rate constant for the oxidation of $34 \mu \mathrm{M}$ reduced cytochrome $c$ was estimated by fitting the curves to a first-order rate law. For polarographic assay, $60 \mu 1$ of reconstituted enzyme (8.36 $\mathrm{mg} / \mathrm{ml}$ ) was incubated with $85 \mu 1$ of lipid on ice under argon for $30 \mathrm{~min}$. The lipid mixture contained DMPC (1 $\mathrm{mg} / \mathrm{ml})$ and, where appropriate, cardiolipin or cardiolipin derivative, dired under argon in the bottom of the sample tube. The lipid was then solubilized in $0.5 \%$ cholate, $10 \mathrm{mM}$ Tris- $\mathrm{HCl}$ and $0.1 \mathrm{mM}$ EDTA (pH 7.4). The final mixture contained $20 \mathrm{~mol}$ of cardiolipin 
or cardiolipin analogue and $100 \mathrm{~mol}$ of DMPC (or 120 mol DMPC) per mol of cytochrome oxidase. The polarographic assay [29] was carried out in $1.3 \mathrm{ml} 25$ $\mathrm{mM}$ potassium cacodylate (pH 7.9), $250 \mathrm{mM}$ sucrose, 7 $\mathrm{mM}$ ascorbate, $0.7 \mathrm{mM}$ TMPD, $100 \mathrm{nM}$ enzyme and 20-12000 nM cytochrome $c$. Binding of cytochrome $c$ to cytochrome oxidase was measured spectrophotometrically [30].

\section{Results}

The effects of lipids on enzyme activity were examined using lipid-substituted beef-heart cytochrome oxidase which contained essentially only DMPC. The lipid substitution procedure $[7,18]$ is not a delipidation; endogenous lipids are replaced by triplicate ammonium sulfate precipitation of the protein in the presence of a 1000 -times molar excess of DMPC solubilized in $0.2 \%$ cholate. The lipid content of the starting material and DMPC-substituted enzyme is given in Table I. Even endogenous cardiolipin, which has an association constant for this intrinsic membrane enzyme 5.3-times that of phosphatidylcholine [7], was displaced efficiently using the DMPC-substitution technique. Thin-layer chromatographic characterization of the lipids extracted from this preparation verified the substitution by DMPC, but if sufficient enzyme was extracted, traces of other components could be detected: phosphatidylethanolamine and possibly monolysocardiolipin, in addition to cardiolipin. Thus the values shown in Table I for the total remaining endogenous lipid, expressed wholly as cardiolipin, are maximal values for the residual cardiolipin content.

Because of the difficulty in removing cardiolipin using delipidation techniques, some workers have suggested that a few moles of cardiolipin comprise a special class, tightly bound by the enzyme, which may be difficult to extract quantitatively from the protein. This concept has been depicted in some structural models for bovine cytochrome $c$ oxidase [31]. In the analysis of residual cardiolipin in the DMPC-exchanged cytochrome oxidase, complete proteolysis followed by methanolysis only slightly increased the amount detected of methyl linoleate (Table I), the marker fatty acid for cardiolipin or other endogenous lipid. The accessibility of these lipids is consistent with previous studies demonstrating that special binding sites for cardiolipin are absent $[7,8]$.

The molecular activity of the DMPC-exchanged cytochrome oxidase after incubation and dialysis with Tween 80 was $9000-11000 \mathrm{~min}^{-1}\left(150-180 \mathrm{~s}^{-1}\right)$, a value which was no different from the activities observed for the starting preparation when treated in the same fashion, and similar to that observed for other preparations containing endogenous lipid [24]. Previous estimates of the activity of these preparations without detergent activation and dialysis gave low activity [7] because the samples had low lipid content and because residual cholate was present. If Tween 80 can replace the function of endogenous lipids, cardiolipin is not essential for the electron transport function for this enzyme. Note, however, that the molecular activities reported above were extrapolated to infinite cytochrome $c$ concentration [24] masking the effects of substrate concentration on the activity of the different preparations.

To study the lipid activation of cytochrome oxidase, a system is necessary which does not include an activating detergent and which reveals effects on substrate-enzyme interactions. Such a system was constructed by cosolubilizing the DMPC-exchanged enzyme with a defined lipid or lipid mixture in $0.2 \%$ cholate followed by assay either spectrophotometrically (oxidation of reduced cytochrome $c$ ) or polarographically (oxygen consumption). Transfer of a small volume of this mixture into the assay media dilutes the cholate to subcritical micelle concentrations, reconstituting the enzyme into lipid bilayers as a model membrane [27]. The effect of cholate, a powerful inhibitor [24], was not entirely eliminated by these dilutions (our unpublished observations).

Cytochrome oxidase reconstituted by cholate-dilution was assayed spectrophotometrically [28] for samples containing cardiolipin and cardiolipin analogues. The results obtained at a non-saturating cytochrome $c$ concentration $(34 \mu \mathrm{M})$ are shown in Fig. 2. The strong dependence of activity on the ratio of lipid to protein

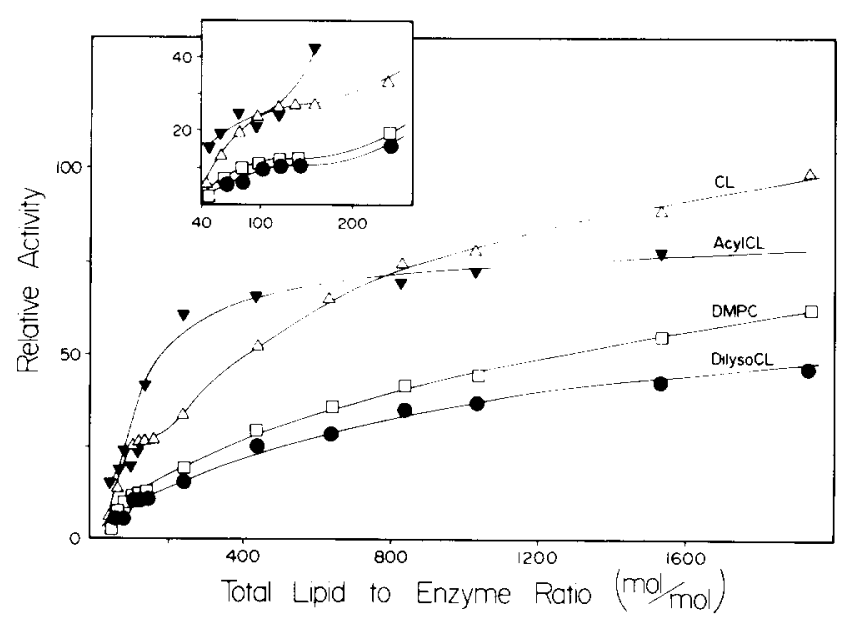

Fig. 2. Lipid activation of cytochrome $c$ oxidase. Cytochrome oxidase exchanged with DMPC to remove endogenous lipid was reconstituted with the lipid indicated: $\triangle$, cardiolipin; $\square$, DMPC; $\mathbf{\nabla}$, acyl cardiolipin; -, dilysocardiolipin. The total lipid content includes the $40 \mathrm{~mol}$ of DMPC per mol of enzyme in the exchanged preparation, plus the added lipid. The relative rate was calculated from the first-order rate constants per $\mathrm{mg}$ of enzyme obtained using $34 \mu \mathrm{M}$ reduced cytochrome $c$ in $40 \mathrm{mM}$ potassium phosphate (pH 6.7) [28]. The rate constant in the presence of $2000 \mathrm{~mol}$ of cardiolipin per mol of enzyme was normalized to a value of 1.0. The inset shows the intermediate plateau region observed for cardiolipin, acyl cardiolipin and DMPC. 
up to about $100 \mathrm{~mol}$ per mol of enzyme is probably related to the amount of lipid required to form a boundary layer around this protein [32,33]. All of the lipids tested were able to activate the enzyme. However, dilysocardiolipin, which is micellar and shows considerable water solubility, did not activate as well as did DMPC. Acylcardiolipin was the most efficient activator in the intermediate range of lipid/protein ratio (100$600 \mathrm{~mol} / \mathrm{mol}$ ), but cardiolipin provided the best activation over the entire range. Note the marked discontinuity observed for cardiolipin (inset to Fig. 2). This reproducible deviation was unique to cardiolipin, possibly because this lipid exhibits the strongest association of the different analogues [19]. All of the lipids continued to activate progressively, at this cytochrome $c$ concentration, up to the highest lipid/protein ratio tested.

For experiments on the substrate concentration dependence of the activity, a fixed total lipid content of $120 \mathrm{~mol}$ of lipid per mol of enzyme was chosen, since this amount was approximately twice that required to form a boundary layer around the enzyme $[4,32,33]$. Enzyme activation by cardiolipin and its analogues was compared at a constant level of $20 \mathrm{~mol}$ per mol of enzyme in the presence of $100 \mathrm{~mol}$ of DMPC per mol of enzyme, as an approximation to the fractional cardiolipin content in the mitochondrial membrane [2]. The total phospholipid to protein ratio in bovine mitochondria is $283-360 \mu \mathrm{g} / \mathrm{mg}$ protein [2], and can be compared with the above ratio, which is approx. 450 $\mu \mathrm{g} / \mathrm{mg}$ cytochrome oxidase. With DMPC constituting the bulk component, the mixture containing the cardiolipin analogues is almost certainly lamellar, even though acylcardiolipin alone, for example, is known to assume a reversed hexagonal phase [19]. The presence of cytochrome oxidase has also been shown to favor formation of the lamellar phase $[53,54]$. The polarographic assay was used to observe the effects of the different cardiolipin analogues on the rate of oxygen uptake as a function of cytochrome $c$ concentration and the data were analyzed as an Eadie-Hofstee plot (Fig. 3). While interpretation of these curves is not straightforward (see Refs. 29 and 34 for a discussion), the slopes can provide estimates of the dissociation constants of cytochrome $c$ from the enzyme-substrate complex [29]. The lowest activity was obtained with DMPC alone; bovine cardiolipin in DMPC supported the highest activity and the different cardiolipin analogues in DMPC supported intermediate activities in the order: dimethylcardiolipin $<$ acylcardiolipin $<$ monolysocardiolipin $\approx$ dilysocardiolipin < cardiolipin. The uncharged phosphotriester groups of dimethyl cardiolipin support an activity only slightly higher than that with DMPC alone, suggesting that the negative charges on the phosphodiesters are important for the activation of the enzyme. Acylcardiolipin (omitted from Fig. 3 for clarity) bears two negatively charged phosphodiester groups, but the

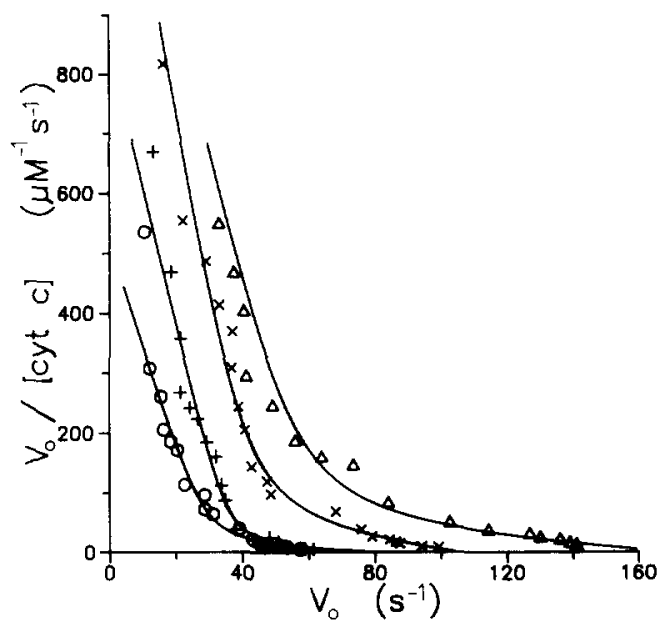

Fig. 3. Eadie-Hofstee plots of the activity of reconstituted cytochrome oxidase. Cytochrome oxidase was reconstituted in DMPC alone at a level of $120 \mathrm{~mol}$ per mol of enzyme (O); in DMPC supplemented with dimethylcardiolipin, 100:20 mol/mol per mol of enzyme $(+)$; in DMPC plus monolysocardiolipin, 100:20 mol $/ \mathrm{mol} \mathrm{per} \mathrm{mol} \mathrm{of} \mathrm{en-}$ zyme $(x)$; or in DMPC plus cardiolipin, 100:20 mol $/ \mathrm{mol}$ per mol of enzyme $(\Delta)$. The oxygen uptake was measured as a function of the cytochrome $\mathrm{c}^{2+}$ concentration over the range $20-12000 \mathrm{nM}$, in low-ionic-strength medium supplemented with TMPD and ascorbate. The solid lines are simulations according to the kinetic scheme of Ref. 46 (see Fig. 5), using the rate constants of Table II, and as described in the text.

polarity of the head group is decreased by esterfication of the normally free hydroxyl of glycerol with a fifth acyl chain. Monolyso- and dilysocardiolipin (the latter also omitted from Fig. 3), with three and two acyl chains respectively, bear an unaltered polar head group with free hydroxyl group and two negative charges, and they both supported the electron transfer activity equivalently. Additional polarity within the phosphatidyl groups of these two lyso lipids apparently left them less able to support activity than cardiolipin itself. These qualitative results are in agreement with those obtained by another group using partially delipidated cytochrome oxidase and a polar head-group-modified cardiolipin [35].

The biphasic behavior shown in Fig. 3 seems intuitively related to cytochrome $c$ binding. However, such studies do not always demonstrate a second binding site [36-40]. Two groups have presented evidence for a low-affinity site for cytochrome $c$ binding at relatively high cytochrome $c$ concentrations, only after binding of cytochrome $c$ at a tighter binding site $[34,38,40]$. Other workers [30], using a method relying on the interaction of cytochrome $c$ with hemes $a$, detect only one binding site.

We have measured the binding of oxidized cytochrome $c$ to DMPC-exchanged cytochrome oxidase using the latter method [30] and observe a strong inflection in the titration corresponding to $1 \mathrm{~mol}$ of cyto- 


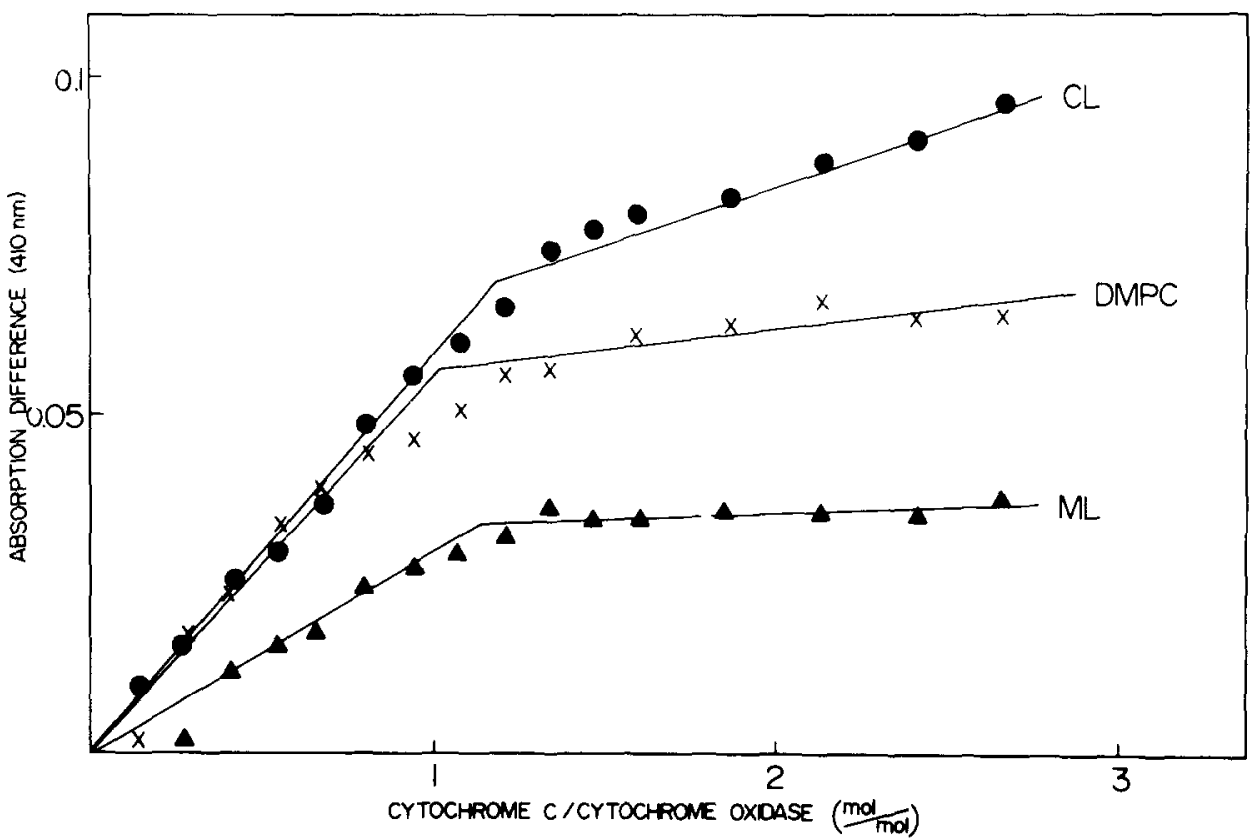

Fig. 4. Spectrophotometric titration of cytochrome oxidase with cytochrome $c$. Cytochrome oxidase was exchanged with DMPC to remove endogenous lipid and then reconstituted with $20 \mathrm{~mol}$ per mol of enzyme of: cardiolipin $(\bullet)$, monolysocardiolipin $(\Delta)$ or DMPC $(\times)$, together with $100 \mathrm{~mol}$ DMPC per mol of enzyme to give a total lipid/protein ratio of $120 \mathrm{~mol} / \mathrm{mol}$. The cytochrome oxidase $(2.5 \mu \mathrm{M})$ was titrated with cytochrome $c^{3+}$ in $25 \mathrm{mM}$ cacodylate, $250 \mathrm{mM}$ sucrose and $0.25 \%$ Tween 20 . The difference spectrum was obtained by subtracting a similar titration in which cytochrome $c$ was confined to a second cuvette which did not contain enzyme but in which the path length and other parameters were identical.

chrome $c$ bound per mol of enzyme (Fig. 4). This inflection occurs in the same place in the absence of cardiolipin (DMPC-exchanged enzyme), as well as in its presence. The titration curve at higher cytochrome $c$ concentrations did not saturate and this effect was particularly noticeable for the enzyme in the presence of cardiolipin. This behavior may indicate additional binding of cytochrome $c$, but the enzyme is known to aggregate in the presence of cardiolipin [41]. The dissociation constants obtained by Michel and Bosshard [30] also provide a reasonable fit to the curves in Fig. 4 and are the same order of magnitude as the value for

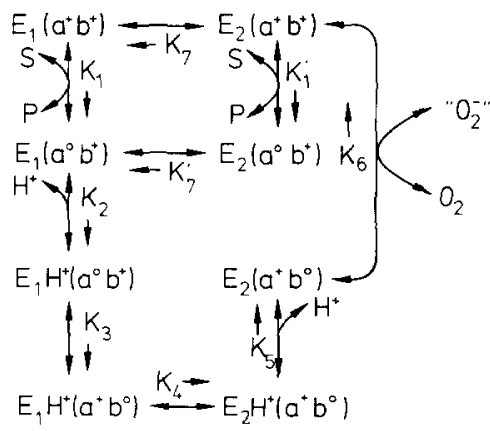

Fig. 5. Schematic reaction cycle for a redox-driven proton pump protein. $E_{1}$ and $E_{2}$ are two different conformations of the enzyme with different affinities for protons ' $a$ ' and ' $b$ ' represent two redox centers in their oxidized $(+)$ and reduced $(O)$ states. ' $S$ ' and ' $P$ ' are substrate (cytochrome $c^{2+}$ ) and product (cytochrome $c^{3+}$ ), respectively. Taken from Ref. 45. the effective high-affinity $K_{\mathrm{m}}$ presented below in Table III.

Several mechanism have been presented recently for the steady-state kinetics of cytochrome oxidase, which describe the biphasic behavior as one of the essential features $[38,42-46]$. A common feature of the most recent models has been different conformational states of the enzyme which differ in their affinity for cytochrome $c$. The model of Brzezinski and Malmström [46] attributes the biphasic behavior to the existence of at least two enzyme conformations, as shown in the kinetic scheme of Fig. 5. Simulation of the substrate depen-

\section{TABLE II}

Rate constants for simulation of kinetics of cytochrome oxidase-lipid complexes

These rate constants were used in the simulation of cytochrome oxidase kinetics using the model of Brzezinski and Malmström [46]. The rate constants for the reverse reactions $\left(k_{-7}\right.$ and $\left.k_{-7^{\circ}}\right)$ were determined by the equilibrium constants given in Ref. 46 . The simulations are shown in Fig. 3.

\begin{tabular}{lllll}
\hline Lipid & $\begin{array}{l}k_{1} \\
\left(\mathrm{M}^{-1} \cdot \mathrm{s}^{-1}\right)\end{array}$ & $\begin{array}{l}k_{1}^{\prime} \\
\left(\mathrm{M}^{-1} \cdot \mathrm{s}^{-1}\right)\end{array}$ & $\begin{array}{l}k_{7} \\
\left(\mathrm{~s}^{-1}\right)\end{array}$ & $\begin{array}{l}k_{7^{\prime}} \\
\left(\mathrm{s}^{-1}\right)\end{array}$ \\
\hline DMPC & $3 \cdot 19^{9}$ & $2 \cdot 10^{7}$ & 33 & 126 \\
DiMeCL & $5 \cdot 10^{9}$ & $1.5 \cdot 10^{7}$ & 43 & 140 \\
AcylCL & $8 \cdot 10^{9}$ & $1.5 \cdot 10^{7}$ & 49 & 126 \\
MonolysoCL & $8 \cdot 10^{9}$ & $7 \cdot 10^{7}$ & 45 & 168 \\
DilysoCL & $8 \cdot 10^{9}$ & $3 \cdot 10^{7}$ & 55 & 210 \\
CL & $8 \cdot 10^{9}$ & $7 \cdot 10^{7}$ & 64 & 420 \\
\hline
\end{tabular}


dence of the enzyme kinetics was carried out according to this model and is given by the solid lines in Fig. 3 . The values of the rate constants which were fitted are given in Table II. The rate constants not listed were taken to have the values given for the Bohr mechanism in Table 2 of Ref. 46. The sole exceptions to this are the equivalent composite rate constants, $k_{2}$ and $k_{-5}$, which depend on the interfacial pH. For the DMPC and dimethylcardiolipin systems, these were given the value $1.3 \cdot 10^{3} \mathrm{~s}^{-1}$, corresponding to the $\mathrm{pH}$ of the assay $(\mathrm{pH}$ 7.9), and for the charged cardiolipin analogues they have been increased to $2.1 \cdot 10^{4} \mathrm{~s}^{-1}$, corresponding to the estimated increase in surface hydrogen ion concentration (see below). The latter was taken to be 1.2 $\mathrm{pH}$ units, from estimates for the surface potential using electrostatic double layer theory (cf. ref. 47). Equilibrium constants were maintained equal to those given in Ref. 46 throughout the simulations, hence maintaining the thermodynamic requirements of the component reaction cycles.

As can be seen from Fig. 3, satisfactory fits are obtained for all the different systems; the biphasic nature of the plots can only be reproduced accurately by adjustment of the rate constants listed in Table II. For the sake of clarity, data and simulations for acyland dilysocardiolipins have been omitted from Fig. 3. The acylcardiolipin plot lies between those for dimethylcardiolipin and monolysocardiolipin and the one for dilysocardiolipin lies close to that for monolysocardiolipin. Similarly good simulations to those shown in Fig. 3 are obtained for both these lipids. The effective catalytic constants, $k_{\text {cat }}$ and $K_{\mathrm{m}}$ for both the high-affinity and low-affinity phases in Fig. 3 have been derived from the rate constants for each system, and are given in Table III.

\section{Discussion}

The molecular activity of DMPC-exchanged cytochrome oxidase was found to be unchanged from that of cytochrome oxidase containing endogenous lipids (including cardiolipin) when the activity was assayed in preparations which had been incubated and dialyzed

\section{TABLE III}

\section{Catalytic parameters for cytochrome oxidase-lipid complexes}

The catalytic parameters are defined in Eqn. 1 and are obtained from the rate constants used for simulation according to the kinetic scheme given in Fig. 5.

\begin{tabular}{lllcl}
\hline Lipid & $\begin{array}{l}k_{\text {cat1 }} \\
\left(\mathrm{s}^{-1}\right)\end{array}$ & $\begin{array}{l}K_{\mathrm{ml}} \\
(\mu \mathrm{M})\end{array}$ & $\begin{array}{l}k_{\text {cat2 }} \\
\left(\mathrm{s}^{-1}\right)\end{array}$ & $\begin{array}{l}K_{\mathrm{m} 2} \\
(\mu \mathrm{M})\end{array}$ \\
\hline DMPC & 28 & 0.056 & 48 & 4.5 \\
DiMeCL & 35 & 0.042 & 46 & 6.6 \\
AcylCL & 42 & 0.031 & 45 & 6.8 \\
MonolysoCL & 39 & 0.029 & 66 & 1.7 \\
DilysoCL & 47 & 0.034 & 74 & 4.8 \\
CL & 53 & 0.039 & 115 & 3.0 \\
\hline
\end{tabular}

with Tween 80 . These observations suggest that cardiolipin was not essential for the activity of cytochrome oxidase [5,7]. However, when the activity of these preparations was studied as a function of lipid/ protein ratio in the absence of detergent (Fig. 2), maximal activities were not obtained unless cardiolipin was present. We attribute these differences to the activitysupporting effects of Tween 80 which seems capable of satisfying a general lipid requirement for the bovine $[10,32]$ as well as for yeast [33] cytochrome oxidase. Of a number of lipids tested, cardiolipin was overall the best activator for the enzyme (Fig. 2). The results shown in Figs. 2 and 4 suggest that cardiolipin may be a good activator for the enzyme at least partially because it binds so well to the enzyme surface [4,5,7]. It is interesting to note that the maximum rate obtained in the presence of cardiolipin at a lipid/protein ratio of 120 $\mathrm{mol} / \mathrm{mol}, k_{\mathrm{ca} 1}+k_{\mathrm{cat} 2}=168 \mathrm{~s}^{-1}$ (Table III), is already equal to the maximum enzymic activity obtained in the presence of an excess of an activating detergent, Tween $80\left(150-180 \mathrm{~s}^{-1}\right)$. At higher lipid/protein ratios, yet higher activities may be obtained in the presence of cardiolipin (cf. Fig. 2). Cardiolipin is also able to produce activation in the presence of Tween 80 (data not shown).

When the activity of the DMPC-exchanged enzyme was studied as a function of cytochrome $c$ concentration (Fig. 3) several conclusions regarding the activation mechanism of cardiolipin could be drawn. The biphasic kinetic behavior obtained in Fig. 3 has previously been related to the presence of acidic lipid providing low-affinity sites for the binding of the cytochrome $c[14,42]$. However, Eadie-Hofstee plots obtained for DMPC-exchanged cytochrome oxidase exhibit the same changes in slope as obtained for samples supplemented with cardiolipin or other cardiolipin analogues (Fig. 3). The results for DMPC-exchanged cytochrome $c$ oxidase reported here demonstrate that the presence of cardiolipin or negatively charged lipid is not essential for the appearance of the biphasic kinetics. A similar conclusion was reached earlier using a cytochrome oxidase isolated from rat liver which contained only $1 \mathrm{~mol}$ of cardiolipin and $1 \mathrm{~mol}$ of phosphatidylinositol per mol of enzyme [55].

The non-hyperbolic kinetics of cytochrome oxidase and the activation by cardiolipin and its derivatives was successfully simulated in terms of the kinetic scheme put forward by Brzezinski and Malmström [46] (solid lines in Fig. 3). The simplified scheme, involving just two redox centers, is depicted in Fig. 5. The differential substrate affinities in the $E_{1}$ and $E_{2}$ conformations give rise to the biphasic kinetics, and the kinetic equation can be expressed in the conventional 'two site' form [46]:

$v_{0} /(\mathrm{E})=k_{\mathrm{cat} 1}(\mathrm{~S}) /\left(K_{\mathrm{m} 1}+(\mathrm{S})\right)+k_{\mathrm{cat} 2}(\mathrm{~S}) /\left(K_{\mathrm{m} 2}+(\mathrm{S})\right)$ 
where $v_{0}$ is the initial velocity and the catalytic coefficients $k_{\text {cat }}$ and the $K_{\mathrm{m}}$ are functions of the rate constants for the individual reaction steps shown in Fig. 5. The results show that this model can describe the kinetics of the lipid-substituted cytochrome oxidase preparations with a reasonable degree of accuracy. The simulations are not totally unique, but, as indicated in the Results section, they do impose certain constraints on the possible mechanisms of cytochrome oxidase activation by cardiolipin.

There are several ways in which cardiolipin may affect the overall catalytic activity, the principal one being electrostatic and conformational. The negative surface charge introduced by cardiolipin will enhance the surface concentration of the two cationic substrates of cytochrome oxidase, namely cytochrome $c$ and hydrogen ions. The surface $\mathrm{pH}$, for instance, is given by:

$\mathrm{pH}=\mathrm{pH}_{0}+\mathrm{e} \Psi / 2.303 k T$

where $\mathrm{pH}_{0}$ is the bulk $\mathrm{pH}$ and $\Psi$ is the (local) surface potential arising from the negatively charged cardiolipin molecules (see, for example, Ref. 47). The surface potential can be estimated from electrostatic double layer theory:

$\Psi=(2 k T / e) \cdot \sinh ^{-1}\left(\sigma /\left(8 N \varepsilon \varepsilon^{0} k T\right)^{1 / 2}\right)$

where $\sigma$ is the surface charge density, $N$ is the counterion concentration (ions $/ \mathrm{m}^{3}$ ) and the other symbols have their usual meanings (see, for example, Ref. 47). The rate constants $k_{2}$ and $k_{-5}$ were then corrected for this electrostatic effect as explained in the Results section. Simulations show that this leads to an increase in activity, but this effect alone is insufficient to describe the features of the activation by cardiolipin completely.

The other rate constants which had to be increased for the simulations in Fig. 3 were those involving the enzyme conformational change $\left(k_{7}\right.$ and $\left.k_{7^{\prime}}\right)$ and the cytochrome $c$ binding $\left(k_{1}\right.$ and $\left.k_{1^{\prime}}\right)$. An electrostatic enhancement of cytochrome $c$ binding is expected for the same reasons as discussed for hydrogen ions, and will be determined by the membrane surface potential (Eqn. 3) and the effective positive charge on the protein. This increased cytochrome $c$ binding may account for the differences in absorption between the DMPC-exchanged enzyme and that supplemented with cardiolipin or monolysocardiolipin seen in Fig. 4. The most interesting finding is that cardiolipin and its analogues modify the environment of the protein in such a way as to facilitate the conformational changes in steps 7 and $7^{\prime}$. Note that the relative concentrations of $E_{1}$ and $E_{2}$ are held constant in the simulation. This increase in the rate of interconversion directly affects the rate-limiting steps in the enzymatic cycle and gives rise to the higher values of $k_{\text {cat }}$. It is also clear from Table III that the various cardiolipins affect this step to different extents, indicating sensitivity to the details of the lipid structure. A possible reason for the conformational effects could lie in the unusual chain composition of the cardiolipin molecule, including the high proportion of polyunsaturated fatty acids, which gives rise to a complicated polymorphic phase behavior of the pure lipid dispersions [19]. In this connection it is significant to note that lipids which tend to form non-lamellar phases have been found to be especially effective in reconstitution of coupled activity for the $\mathrm{Ca}^{2+}$-ATPase [49].

In conclusion, cardiolipin is capable of efficiently activating cytochrome $c$ oxidase, but is neither absolutely essential for maintaining activity nor responsible for the biphasic kinetics of the enzyme. Of the several analogues of cardiolipin tested, cardiolipin itself was most effective in activating the enzyme. Structural features which were important in the activation were the presence of the two negative charges within the polar head-group unobstructed by substitution on the intervening glycerol group. This activation of cytochrome oxidase by cardiolipin and its derivatives can be simulated using the kinetic scheme put forward by Brzezinski and Malmström [46]. Electrostatic enhancement of the surface concentration of the substrates, and facilitation of the transition between two conformations of the enzyme seem to be the essential components of the activation. The possibility that a conformational shift in the enzyme (Refs. 50, 51 but see Ref. 52), which is a feature of other models $[40,43,45]$, is induced by the cardiolipin analogues also cannot be excluded. Such mechanisms may also be applicable to other cardiolipin-dependent enzymes in the inner mitochondrial membrane.

\section{Acknowledgements}

We gratefully acknowledge support from the American Heart Association, from the National Science USAFRG Cooperative Science Program and from the US Public Health Service (HL 38190). We are grateful to P. Brzezinski and B.G. Malmström, Göteborg, Sweden, for providing us with their model and for discussions with H.R. Bosshard, Zürich, Switzerland. E.A.E. Garber and E. Margoliash, Evanston, IL, kindly shared their manuscript with us before publication.

\section{References}

1 Owen, C.S. and Wilson, D.F. (1974) Arch. Biochem. Biophys. 161, 581-591.

2 Daum, G. (1985) Biochim. Biophys. Acta 822, 1-42.

3 Cable, M.B., Jacobus, J. and Powell, G.L. (1978) Proc. Natl. Acad. Sci. USA 75, 1227-1231.

4 Cable, M.B. and Powell, G.L. (1980) Biochemistry 19, 5679-5686.

5 Knowles, P.F., Watts, A. and Marsh, D. (1981) Biochemistry 20 , $5888-5894$. 
6 Marsh, D. (1983) Trends Biochem. Sci. 8, 330-333.

7 Powell, G.L., Knowles, P.F. and Marsh, D. (1985) Biochim. Biophys. Acta 816, 191-194; 821 (1985) 507.

8 Fowler, W.T. and Powell, G.L. (1988) Chem. Physics Lipids 47, 261-271.

9 Awasthi, Y.C., Chuang, T.F., Keenan, T.W. and Crane, F. (1971) Biochim. Biophys. Acta 226, 42-52.

$10 \mathrm{Yu}, \mathrm{C}$, Yu, L. and King, T.E. (1975) J. Biol. Chem. 252, 1383-1392.

11 Robinson, N.C., Stry, F. and Talbert, L. (1980) Biochemistry 19, 3656-3661.

12 Robinson, N.C. (1982) Biochemistry 21, 184-188.

13 Fry, M. and Green, D. (1980) Biochem. Biophys. Res. Commun. $93,1238-1246$.

14 Vik, S.B., Georgevich, G. and Capaldi, R.A. (1981) Proc. Natl. Acad. Sci. USA 78, 1456-1460.

15 Birrell, G.B. and Griffith, O.H. (1976) Biochemistry 15, 2925-2929.

16 Capaldi, R.A., Darley, Usmar, V., Fuller, S. and Millet, F. (1982) FEBS Lett. 138, 1-7.

17 Bisson, R., Jacobs, B. and Capaldi, R.A. (1980) Biochemistry 19, 4173-4178.

18 Watts, A., Marsh, D. and Knowles, P.F. (1978) Proc. Natl. Acad. Sci. USA 78, 1456-1460.

19 Powell, G.L. and Marsh, D. (1985) Biochemistry 24, 2902-2908.

20 Powell, G.L., Knowles, P.F. and Marsh, D. (1987) Biochemistry $26,8138-8145$.

21 Lowry, O.H., Rosebrough, N.J., Farr, A.L. and Randall, R.J. (1951) J. Biol. Chem. 193, 265-275.

22 Lowry, R.R. and Tinsley, I.J. (1974) Lipids 9, 491-492.

23 Eibl, H. and Lands, W.E. (1969) Anal. Biochem. 30, 51-57.

24 Yonetani, T. (1966) Biochem. Prep. 11, 14-20.

25 Vigh, L., Joo, F., Droppa, M., Horvath, L.I. and Horvath, G. (1985) Eur. J. Biochem. 147, 477-481.

26 Poyton, R.O. and McKemmie, E. (1979) J. Biol. Chem. 254, 6763-6771.

27 Warren, G.B., Toon, P.A., Birdsall, N.J.M., Lee, A.G. and Metcalfe, J.C. (1974) Biochemistry 13, 5501-5507.

28 Yonetani, T. and Ray, G.S. (1965) J. Biol. Chem. 240, 3392-3398.

29 Brautigan, D.L., Ferguson-Miller, S. and Margoliash, E. (1978) Methods Enzymol. 53, 155-164.

30 Michel, B. and Bosshard, H.R. (1984) J. Biol. Chem. 259, 1008510091.

31 Frey, T.G., Costello, M.J., Karlsson, B., Haselgrove, J.C. and Leigh, J.S. (1982) J. Mol. Biol. 162, 113-130.

32 Jost, P., Griffith, O.H., Capaldi, R.A. and Vanderkooi, G. (1973) Biochim. Biophys. Acta 311, 141-142.
33 Knowles, P.F., Watts, A. and Marsh, D. (1979) Biochemistry 18, $4480-4487$.

34 Osheroff, N., Speck, S., Margoliash, E., Veerman, E.C.I., Wilms, J., Konig, B.W. and Muijsers, A.O. (1963) J. Biol. Chem. 258 , 5731-5738.

35 Dale, M.P. and Robinson, N.C. (1988) Biochemistry 27, 8270 8275 .

36 Orin, Y., Sekuzu, I. and Okunuki, K. (1926) J. Biochem. (Tokyo) $51,204-215$.

37 Nichols, P. (1964) Arch. Biochem. Biophys. 106, 25-48.

38 Peterson, L.C. (1978) FEBS Lett. 94, 105-108.

39 Garber, E.A.E. and Margoliash, E. (1990) Biochim. Biophys. Acta $1015,279-287$.

40 Reider, R. and Bosshard, H.R. (1978) J. Biol. Chem. 253, 60456053.

41 Kim, K., Abramovitch, D.A. and Powell, G.L. (1988) FASEB J. 2, A578.

42 Speck, S.H., Dye, D. and Margoliash, E. (1983) Proc. Natl. Acad Sci. USA $81,347-351$.

43 Wilms, J., Veerman, E.C.I., Konig, B.W., Dekker, H.L. and Van Gelder, B.F. (1981) Biochim. Biophys. Acta 635, 13-24.

44 Sinjorgo, K.M.C., Steinbach, O.M., Dekker, H.L. and Muijsers, A.O. (1986) Biochim. Biophys. Acta 850, 108-115.

45 Michel, B. and Bosshard, H.R. (1989) Biochemistry 28, 244-252.

46 Brzezinski, P. and Malmström, B.G. (1986) Proc. Natl. Acad. Sci. USA $83,4282-4286$.

47 Cevc, G. and Marsh, D. (1987) Phospholipid Bilayers. Physical Principles and Models. Wiley-Interscience, NY.

48 Ferguson-Miller, S., Brautigan, D.L. and Margoliash, E. (1976) J. Biol. Chem. 251, 1104-1115.

49 Navarro, J., Toivio-Kinnucan, M. and Racker, E. (1984) Biochemistry $23,130-135$

50 Weber, C., Michel, B. and Bosshard, H.R. (1987) Proc. Natl. Acad. Sci. USA 84, 6687-6691.

51 Copeland, R.A., Smith, P.A. and Chan, S.I. (1987) Biochemistry 26, 7311-7316.

52 Ferreira-Rajabi, L. and Hill, B.C. (1989) Biochemistry 28, 80288032.

53 Rietveld, A., Van Kemenade, T.J.J.M., Hak, T., Verkleij, A.J. and De Kruiff,, B. (1987) Eur. J. Biochem. 164, 137-140.

54 Powell, G.L., Knowles, P.F. and Marsh. D. (1990) Biochemistry $29,5127-5132$.

55 Thompson, D.A. and Ferguson-Miller, S. (1983) Biochemistry 22, $3178-3187$. 